\title{
Preparation and characterization of bionanocomposite films based on wheat starch and reinforced with cellulose nanocrystals
}

\author{
Belén Montero 1 - Maite Rico - Luis Barral - Rebeca Bouza · Joaquín López • \\ Anja Schmidt • Birgit Bittmann-Hennes
}

Received: 24 January 2021 / Accepted: 14 June 2021 / Published online: 4 July 2021

(C) The Author(s) 2021, corrected publication 2021

\begin{abstract}
In recent times, the attention of scientific community has been focusing on the replacement of petroleum-based polymers by others more environmentally friendly. In this sense, bionanocomposites based on glycerol-plasticized wheat starch and reinforced with cellulose nanocrystals (CNCs) were prepared by a solvent-casting process to obtain environmentally friendly films. The plasticization process was proven to be complete in the conditions used and no residual crystallinity was observed in any case. The incorporation of CNCs leads to materials with increased rigidity (about $1000 \%$ increment in modulus) which is related to a good filler-matrix interaction and to the formation of a rigid crystalline network of cellulose. This fact allowed also to
\end{abstract}

B. Montero $(\bowtie) \cdot$ M. Rico $~$ L. Barral .

R. Bouza · J. López

Grupo de Polímeros, Departamento de Física y Ciencias

de la Tierra, Universidade da Coruña, Escuela

Universitaria Politécnica, Serantes, Avda. 19 de Febrero

s/n, 15471 Ferrol, Spain

e-mail: belen.montero@udc.es

L. Barral

Cellular and Molecular Cardiology Research Unit, Institute of Biomedical Research (IDIS-SERGAS), University Clinical Hospital, Santiago de Compostela, Spain

A. Schmidt · B. Bittmann-Hennes Institut Für Verbundwerkstoffe $\mathrm{GmbH}$, ErwinSchrödinger-Str. Geb. 58, 67663 Kaiserslautern, Germany improve the moisture resistance and the barrier properties (in both, oxygen and water vapor as permeant) of the bionanocomposite films due to the formation of a tortuous path, which prevent the gas diffusion. Moreover, the thermal stability of films was not affected by the filler incorporation. These improvements in the properties make these films susceptible to be used in short-time applications in the food packaging industry.

Keywords Thermoplastic starch · Solvent casting · Bionanocomposite films · Wheat starch · Cellulose nanocrystals

\section{Introduction}

The reduction and elimination of petroleum-based plastic waste has become a matter of concern for the environment during the last decades. The quantity of residues generated is increasing with the development of the global daily activity. Their poor biodegradability makes difficult their reduction or elimination, leading to their storage for large periods of time. In addition to the waste problem, the low availability as well as the exploitation of fossil resources makes necessary to find an alternative. The preparation of completely biodegradable polymeric materials, which come from renewable natural resources and have a high availability in the environment, can be the perfect 
alternative to replace the polymers from fossil sources (Reddy et al. 2013). However, biopolymers with similar properties to the synthetic ones have not been obtained yet so the enhancement of their properties continues to be an objective to reach.

Starch is becoming a great candidate to prepare biopolymers as an alternative to synthetic polymers in situations where long-term durability is not a requirement. Starch is the second most abundant product in the nature after the cellulose and it can be easily obtained from a wide range of renewable vegetable sources. It is found basically into their roots or seeds as granules of different shapes and sizes, depending on the botanical origin, and it represents the main plant energy reserve (Montero et al. 2017). The extraction is relatively easy and low cost and, as a vegetal origin product, is completely biodegradable (Emmambux and Taylor 2013). To get a thermoplastic polymer from raw starch granules, they must be treated with the adequate plasticizer to enable melting below the decomposition temperature of starch. Temperature and shear conditions must be applied to yield a material where the starch forms a continuous polymeric entangled phase known as thermoplastic starch (TPS). Thermoplastic starches have been recently used as the basis of materials with several applications in the food packaging industry. Khan et al. summarized numerous studies related to the production of biodegradable TPS food packaging materials (Khan et al. 2017). More recently, Cheng et al. used cellulose nanocrystals (CNCs), cellulose nanofibers (CNFs), and microfibrillated celluloses (MFCs) as a reinforcement for starch obtaining highperformance starch nanocomposites by film casting. (Cheng et al. 2019).

However, starch-based biocomposites show poor mechanical, thermal and barrier properties compared to the synthetic ones. Moreover, these properties are very sensitive to the moisture content and become worse with time because of the retrogradation phenomena, which is the reason why the TPS applications are more focused on shorter times. Therefore, it is necessary to make some improvement in these properties to obtain suitable materials for each application. The use of nanoscale reinforcements derived from renewable resources was one of the strategies previously used and has proven to be an effective method to overcome the mentioned drawbacks. In this way, reinforcements in the nanoscale as nanoclays (Zeppa et al. 2009), starch nanocrystals (Farrag et al. 2018) or cellulose nanocrystals (Rico et al. 2016; Zainuddin et al. 2013) have been used to improve the properties of different starch-based materials.

Cellulose is a structural component of plants widely present in nature and easy to obtain as cellulose fibrils by relatively simple methods from renewable resources. Moreover, cellulose is completely biodegradable, so combined with the starch matrix, an environmentally friendly biocomposite can be prepared (Tan et al. 2019). Cellulose nanoparticles can be obtained by acid hydrolysis of cellulose fibrils and have been widely used as nano-additive in thermoplastic starch in order to improve the mechanical and barrier properties as well as to avoid the swelling phenomenon (George and Sabapathi 2015). Cellulose nanoparticles have a similar structure to starch and the presence of a high number of hydroxyl groups in the crystal surface allows the formation of hydrogen bonds and the good adhesion and dispersion into the matrix. The reinforcing potential of cellulose nanocrystals is basically due to its semicrystalline nature and the high aspect ratio, while, their structure allows the chains flexibility which counteracts the dimensional changes due to swelling (Mariano et al. 2014). Moreover, it was reported that the formation of a crystalline cellulose network provides rigidity to the material and improves the resistance to water molecules permeability (Reddy 2013).

The aim of this work was to obtain and characterize bionanocomposites based on wheat starch and reinforced with cellulose nanocrystals, which come from renewable natural resources and they are expected to be environmentally friendly. These bionanocomposite films were analyzed by using several techniques in a wide and exhaustive characterization, which has no precedents in the bibliography according to the authors knowledge. The surface morphology, crystallization behavior and plasticization completion were widely analyzed by using a variety of techniques such as scanning electron microscopy (SEM), X-ray diffraction (XRD) and attenuated total reflectance Fourier transform infrared spectroscopy (ATR/FTIR). A special emphasis was made in the study of the effect of cellulose nanocrystals content in the mechanical resistance and viscoelastic behavior of these bionanocomposites by dynamic mechanical analysis (DMA). Thermal stability and degradation process of bionanocomposites was also analyzed by 
thermogravimetric analysis (TGA). Finally, a special attention was paid to the response of the bionanocomposites obtained with regard to the moisture and swelling when they were exposed to high humidity conditions. These studies were completed with the analysis of the filler influence in the water vapor and oxygen permeability through the thermoplastic starch matrixes. This wide characterization demostrated that the addition of CNCs to the thermoplastic wheat starch leads to environmentally friendly bionanocomposite films with enhanced mechanical and barrier properties, which are suitable for applying in food packaging industry, where the mechanical resistance and the permeability to gas molecules of the films is crucial.

\section{Experimental section}

\section{Materials}

Native wheat starch (WS) with an amylose content of $25 \%$, according to the supplier data, was kindly provided by Roquette Freres S. A. (France). The granule size was measured by laser granulometry in a Beckman Coulter LS $^{\mathrm{TM}} 200$ granulometer (Spain), equipped with a micro volume module (MVM) and a variable speed fluid module (VSM +) obtaining values of $\mathrm{D}_{10}=11.7 \mu \mathrm{m}, \quad \mathrm{D}_{50}=21.3 \mu \mathrm{m} \quad$ and $\mathrm{D}_{90}=30.6 \mu \mathrm{m}$. The measurement interval of the granulometer was between $0.4 \mu \mathrm{m}$ and $2000 \mu \mathrm{m}$. Wheat starch was maintained in a desiccator at a $40 \%$ relative humidity $(\mathrm{RH})$ at room temperature, for at least $24 \mathrm{~h}$ before the preparation of films. As plasticizer, glycerol $\left(\mathrm{C}_{3} \mathrm{H}_{8} \mathrm{O}_{3}\right.$, Gly), with a purity of $99.5 \%$ and a molar mass of $92.09 \mathrm{~g} \cdot \mathrm{mol}^{-1}$, provided by Sigma-Aldrich S. A. (Spain), was used as received. Cellulose nanocrystals (CNCs), provided by University of Maine (USA) as rod -like crystals with a width of (5-20) nm and a length of (150-200) nm, were used as filler.

Saturated aqueous solutions of analytical grade salts were used to create different relative humidity (RH) environments with values of $95 \%$ (potassium nitrate, $\mathrm{KNO}_{3}$ ), $75 \%$ (sodium chloride, $\mathrm{NaCl}$ ) and $54 \%$ (magnesium nitrate hexahydrate, $\mathrm{Mg}\left(\mathrm{NO}_{3}\right) \cdot 6 \mathrm{H}_{2} \mathrm{O}$ ). All the salts were purchased from Scharlab S. L. (Spain).
Preparation of neat TWS and TWS/CNC nanocomposites

The films of thermoplastic wheat starch (TWS) were manufactured using the solution casting method with a glycerol content fixed at $30 \mathrm{wt} \%$ on the dry starch basis. Solutions of native starch $(2.1 \mathrm{~g})$ and glycerol $(0.9 \mathrm{~g})$ were prepared and mixed to obtain the neat TWS films. Suspensions of cellulose nanocrystals were added to the former mixture to get the TWS modified with CNC nanocomposites (TWS/CNC). All the solutions were taken to a final volume of $60 \mathrm{~mL}$ of distilled water and manually stirred with a glass bar until obtaining a homogeneous dispersion. CNC composition was $1 \mathrm{wt} \%, 2 \mathrm{wt} \%$ and $5 \mathrm{wt} \%$ relative to the total dry mass. The resulting solutions were heated in a microwave oven with stirring in order to obtain the corresponding thermoplastic starch gel, which was charged into a $10 \mathrm{~cm}$ diameter glass petri dish previously lined with a Teflon sheet. Films of neat TWS and TWS/CNC nanocomposites, with thickness of $(0.14 \pm 0.02) \mathrm{mm}$, were obtained after being dried in a non-ventilated oven at $30{ }^{\circ} \mathrm{C}$ for $30 \mathrm{~h}$.

Prior to testing, the resulting films were preconditioned in a climate chamber at room temperature and $40 \% \mathrm{RH}$ for $72 \mathrm{~h}$ to ensure the equilibration of water in the films. Codification used was TWS for the unfilled film and TWS1CNC, TWS2CNC and TWS5CNC for TWS/CNC with $1 \mathrm{wt} \%, 2 \mathrm{wt} \%$ and $5 \mathrm{wt} \%$ of cellulose nanocrystals, respectively.

\section{Characterization techniques}

\section{Scanning electron microscopy (SEM)}

The surface morphologies of both, native starch granules and thermoplastic starch films, were examined using a scanning electron microscope (JEOLJSM 6400, Japan) operated at $20 \mathrm{kV}$. Samples were sputtered with a thin layer of gold previously.

\section{$X$-ray diffraction $(X R D)$}

X-ray diffraction patterns were recorded in a diffractometer D5000 Siemens (Germany) operated at a voltage of $45 \mathrm{kV}$ and a current of $30 \mathrm{~mA}$. A copper $\mathrm{K}$-alpha $(\mathrm{Cu} \mathrm{K} \alpha)$ radiation was used with an average wavelength of $\lambda(\mathrm{K} \alpha)=0.15 \mathrm{~nm}(1.54 \AA)$. The aperture was $0.6 \mathrm{~mm}$. Diffractograms were registered in 
the angular region of $2 \theta$ from $4^{\circ}$ to $40^{\circ}$, at room temperature, with a time step of $4 \mathrm{~s}$ and an angular increment of $0.005^{\circ}$.

\section{Attenuated total reflectance Fourier transform infrared spectroscopy (ATR/FTIR)}

FTIR spectra were recorded on a Bruker Vector 22 FTIR spectrometer (Germany) equipped with a Specac Golden Gate ${ }^{\mathrm{TM}}$ heated single-reflection diamond attenuated total reflection (ATR) system (UK). The analysis were made over 100 consecutive scans with a resolution of $4 \mathrm{~cm}^{-1}$ from 4000 to $400 \mathrm{~cm}^{-1}$ at room temperature.

\section{Dynamic mechanical analysis (DMA)}

The films were cut into rectangular strips $20 \times 4 \mathrm{~mm}^{2}$. The thickness of the strips was measured in 5 points with a micrometer, the average of each sample was calculated and the resulting values were in the range of $(0.12 \pm 0.02) \mathrm{mm}$. The thermomechanical behavior was tested with a dynamomechanical analyzer, DMA 7, from Perkin Elmer (USA) in the extension mode. The temperature range between $-70{ }^{\circ} \mathrm{C}$ and $50{ }^{\circ} \mathrm{C}$ was used at a heating rate of $2{ }^{\circ} \mathrm{C}$ $\min ^{-1}$ with a frequency of $1 \mathrm{~Hz}$ under a $20 \mathrm{~mL} \cdot \mathrm{min}^{-1}$ helium flow. The set up allowed determining the storage modulus $E^{\prime}$, the loss modulus $E^{\prime \prime}$ and the ratio of these two parameters, $\tan \delta=E^{\prime \prime} / E^{\prime}$, named as loss factor.

\section{Thermogravimetric analysis (TGA)}

Thermogravimetric analysis was performed using a Perkin Elmer TGA-7 microbalance with a platinum sample pan (USA). Approximately 3-5 mg of material were heated from 50 to $600{ }^{\circ} \mathrm{C}$ at $10{ }^{\circ} \mathrm{C} \cdot \mathrm{min}^{-1}$ with a $20 \mathrm{~mL} \cdot \mathrm{min}^{-1}$ argon flow. The thermogravimetric (TG) curves and their first derivatives, the DTG curves, were recorded in each test.

\section{Water absorption}

The water absorption capacity was determined by a gravimetric method in square shaped pieces of $8 \mathrm{~mm}$ side. Pieces were dried in an air-circulating oven at $70{ }^{\circ} \mathrm{C}$ for $72 \mathrm{~h}$ and allowed to cool in a hermetic glass with an $8 \%$ relative humidity $(\mathrm{RH})$. They were weighted after cooling to determinate the initial mass $\left(M_{0}\right)$ before being placed in hermetic glass containers conditioned at $20 \pm 2{ }^{\circ} \mathrm{C}$. Each container has been filled with a saturated solution of one of the three salts used to obtain the \% RH environment at 54\%, $75 \%$ and 95\%, as it is described in the UNE-EN ISO 2006:483. The percentage of water absorbed by the samples at each time (water uptake, $W$ ) was calculated according to Eq. 1

$W(\%)=\frac{M_{t}-M_{0}}{M_{0}} \cdot 100$

where $M_{t}$ is the weight at time $t$, and $M_{O}$ is the initial weight of the total dry sample.

\section{Permeability}

Water vapor transmission rate ( $W V T R)$ was measured in films, with a thickness of $(0.08 \pm 0,01) \mathrm{mm}$, in a PERMATRAN-W®1/50 system from MOCON GmbH (Germany) according to ASTM E-398. The cell temperature was $37.8{ }^{\circ} \mathrm{C}$ and relative humidities of 5\% and $40 \%$ were applied in two sides of the films as driving force of the test.

Oxygen vapor transmission rate $(O T R)$ was measured according to ASTM D-3985 using an OXTRAN®1/50 system from MOCON GmbH (Germany). All the films, with a thickness of $(0.07 \pm 0,01)$ $\mathrm{mm}$, were measured at $23{ }^{\circ} \mathrm{C}$. One side of the film was exposed to dry oxygen flow, relative humidity of $3 \%$, with a pressure of 27.7 psi.

In both cases, the thicknesses of the films were measured with a digital precision gauge from Baxlo model 3050 (Spain). The data reported was the average, resulting of three measurements. The film surface was reduced to an area of $5 \mathrm{~cm}^{2}$ with metallic masks sealed with epoxy glue. The tests were done by obtaining a steady line for transmission rate under continuous mode. Transmission rate of three replicate samples were tested. The resulting values given come from the average value obtained from them.

\section{Results and discussion}

Morphological aspects

The morphologies of TWS and TWS/CNC film surfaces, were analyzed by SEM (Fig. 1). 
The image of TWS (Fig. 1a) shows a continuous surface, without crumples or holes. The lack of starch aggregates or swollen granules in the surface image indicates the glycerol molecules were capable of penetrating in the starch structure and to form hydrogen bonds with the hydroxyl groups of starch molecules, completing the plasticization process in an adequate way. Incorporation of cellulose nanoparticles makes the matrix rougher as can be seen (Fig. 1bd). Nanocomposites with the lower CNC contents show a good dispersion of the filler in the starch matrix. The similarity between the chemical structures of cellulose and starch, the nanometric size effect of lower CNC contents ( $1 \mathrm{wt} \%$ and $2 \mathrm{wt} \%$ ) and the formation of hydrogen bonds between filler and matrix are factors that favor the uniform $\mathrm{CNC}$ distribution into the matrix (Cao et al. 2008). As the CNC content increases to $5 \mathrm{wt} \%$, the dispersion inside the matrix gets worse leading to the appearance of large filler aggregates.

\section{X-ray diffraction analysis (XRD)}

Figure 2a, shows the X-ray diffractograms for pure CNCs as well as for native wheat starch (WS) and for thermoplastic wheat starch (TWS). The CNCs show the typical profile described in bibliography for cellulose type I (Dufresne and Castaño 2016), with peaks at $2 \theta=14.5^{\circ}, 16.8^{\circ}, 22.6^{\circ}$ and $34.7^{\circ}$. The native starch granules show different crystalline structures depending on their source. These crystalline regions existing in starch granules are constituted by an arrangement of amylopectin short chains in a cluster form. In case of cereal starches, the characteristic structure is formed by amylopectin chains ordered in an orthogonal packing of double helices with a small content of intracrystalline water. This is known as A-type structure which shows a diffraction pattern with two peaks at $2 \theta$ values at $15.1^{\circ}$ and $23.1^{\circ}$ and a doublet with peaks at $17.2^{\circ}$ and $18.1^{\circ}$, as can be seen in the diffraction profiles of WS granules reported (Lomelí-Ramírez et al. 2014; Teixeira et al. 2009).

The plasticization process leads to a disorganization of starch structure, the granular disruption occurs causing the disappearance of A-type structure peaks in the $\mathrm{x}$-ray diffraction profiles, which evolve towards profiles with a high amorphous scanning halo, typical of semi-crystalline thermoplastic starches as can be

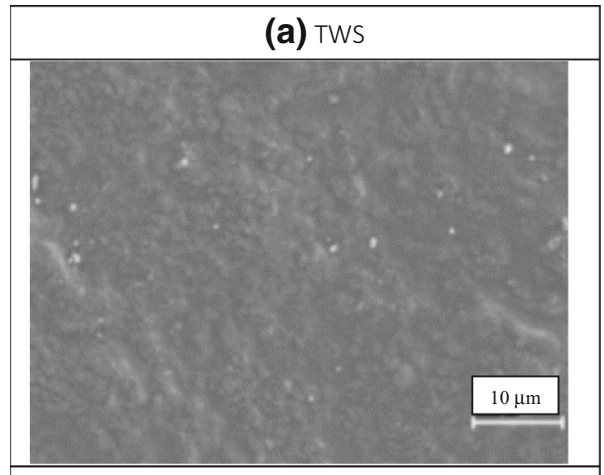

(b) TWS1CNC

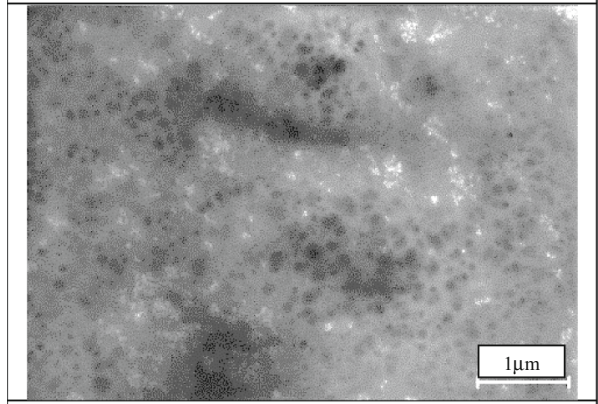

(c) TWS2CNC
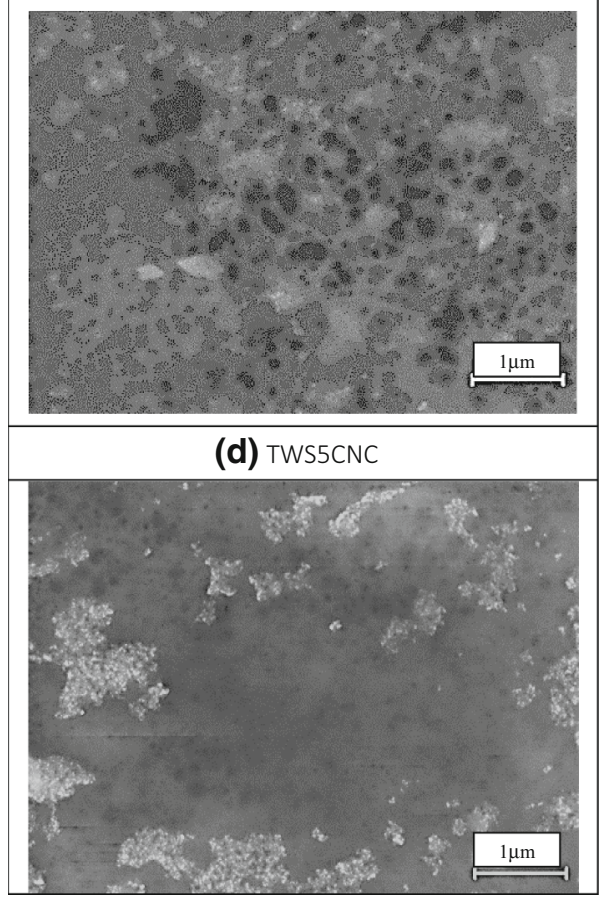

Fig. 1 SEM images of neat plasticized wheat starch (a) and biocomposites with CNC contents of $1 \mathrm{wt} \%$ (b), $2 \mathrm{wt} \%$ (c) and $5 \mathrm{wt} \%(\mathbf{d})$ 

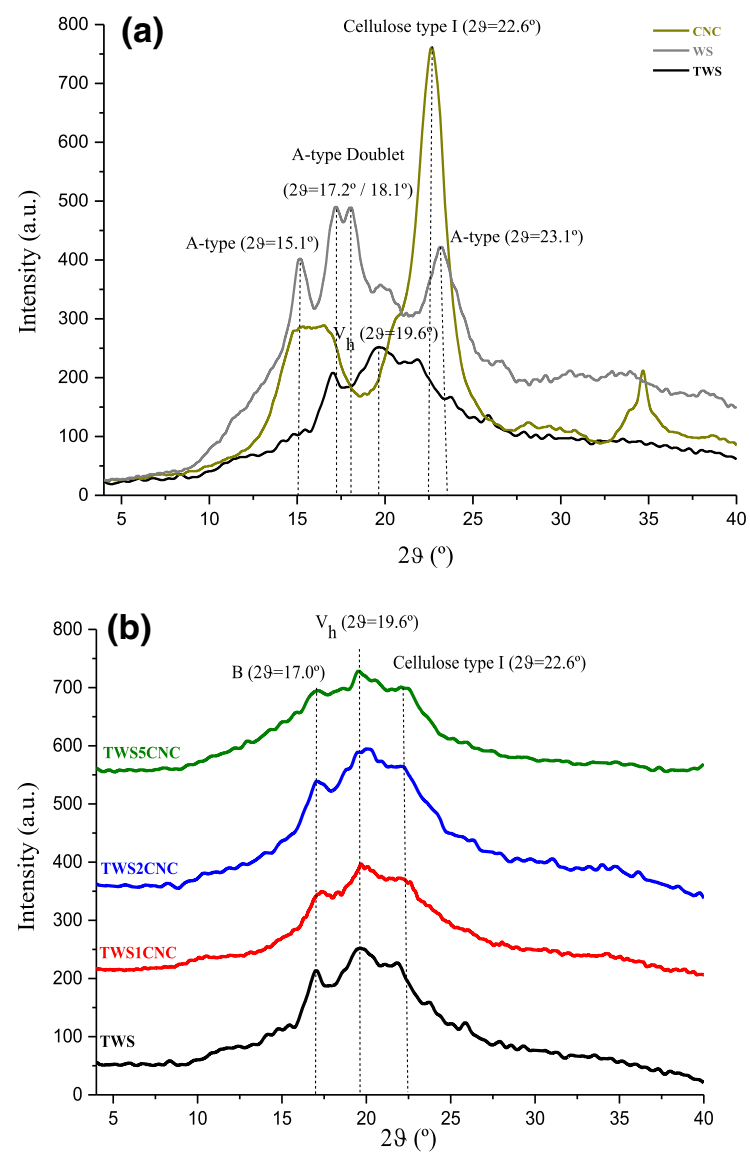

Fig. 2 X-ray diffractograms of (a) wheat starch granules (WS), pure CNCs and plasticized wheat starch film (TWS) and (b) plasticized starch films filled with $1 \mathrm{wt} \%, 2 \mathrm{wt} \%$ and $5 \mathrm{wt} \%$ CNC compared to TWS

seen in TWS profiles (Fig. 2a and b) and TWS/CNC profiles (Fig. 2b) (Kaushik et al. 2010).

Moreover, thermoplastic starches can present two crystalline structures: (i) residual crystallinity and (ii) processing-induced crystallinity. Residual crystallinity occurs when the starch granules disruption is not completed during plasticization process so that amylopectin molecules with the native A-type structure remain in the TPS or when the reorganization of amylopectin short chains into the native double helices arrangements takes places during casting. By comparison of WS granules and plasticized films diffraction profiles, residual crystallinity cannot be observed neither in the unfilled film (TWS) nor in TWS/CNC nanobiocomposites. The peaks at $23.1^{\circ}$ and $15.1^{\circ}$ disappear as occurs with the doublet $\left(17.2^{\circ}\right.$ and $\left.18.1^{\circ}\right)$, which cannot be distinguished due the appearance of amorphous halo as a consequence of the plasticization process.

Processing-induced crystallinity occurs due to the dissociation of the amylose linear chains out of the starch granules and the recrystallization into an amylose-plasticizer complex. This complex shows an arrangement of a single helix maintained through hydrogen bonds, which can be organized in several crystalline structures such as the named $\mathrm{V}_{\mathrm{h}}$ and $\mathrm{V}_{\mathrm{a}}$ structures. The characteristic peaks for each arrangement are described as follows: the $\mathrm{V}_{\mathrm{h}}$-type appears at $2 \theta=19.6^{\circ}$ and it corresponds with a hydrated structure formed by helices composed of six or seven glucose residues (Nishiyama et al. 2010). It can be transformed into the $\mathrm{V}_{\mathrm{a}}$-type structure under dehydration conditions (peak at $2 \theta=20.6^{\circ}$ ). The $\mathrm{V}_{\mathrm{h}}$-type peak, more stable and predominant in humid conditions, is clearly differentiated in the center of the amorphous halo in the TWS profile. Films were stored in a desiccator at about $40 \% \mathrm{RH}$ during the time before the test, however, a peak at $2 \theta=17.0^{\circ}$ appears corresponding with the amylopectin recrystallization in the B-type structure, which occurs during the storage. The intensity of this peak decreases when the crystalline cellulose nanocrystals are incorporated into the films. The same occurs with the intensity of the $\mathrm{V}_{\mathrm{h}^{-}}$ type peaks mentioned above. The presence of CNCs causes an increase on the starch matrix rigidity preventing the reorganization of amylose and amylopectin chains. The peaks at lower $2 \theta$ values for CNC profile are overlapped with some peaks belonging to TWS and TWS/CNC profiles but, the peak at $2 \theta=22.6^{\circ}$ can be perfectly distinguished, especially in the sample with $5 \mathrm{wt} \% \mathrm{CNC}$, which indicates the cellulose nanocrystals do not lose the crystalline structure in TPS composites.

\section{ATR-FTIR analysis}

FTIR spectroscopy was used for identifying the interactions between starch chains, glycerol molecules and cellulose nanoparticles formed during plasticization process as well as to investigate possible changes in the thermoplastic starch structure on a short-range molecular level. Spectra profiles obtained for raw wheat starch granules (WS) were recorded and compared with the spectra obtained from neat plasticized wheat (TWS) and CNC filled nanocomposites (TWS/CNC) Fig. 3. 


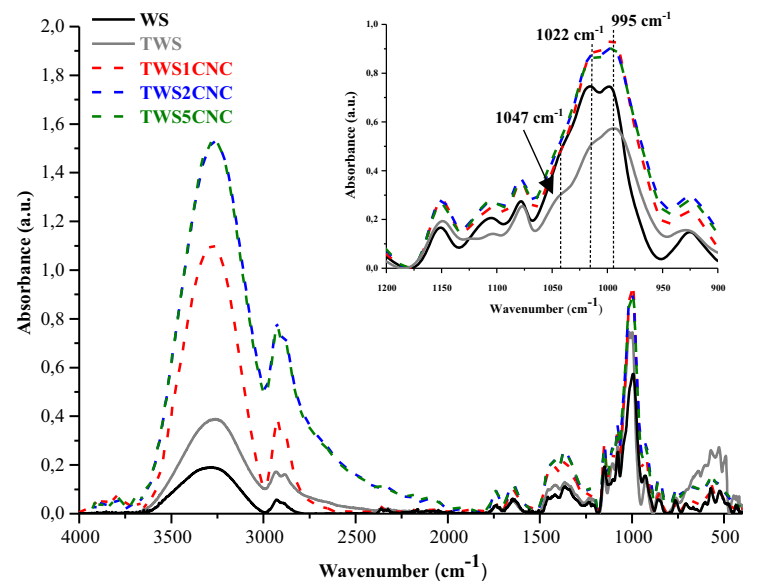

Fig. 3 FTIR spectra obtained for wheat starch granules (WS), plasticized starch (TWS) and TWS/CNC films

In comparison to the raw starch, the spectra profile does not suffer any change in the bands appearing or in their positions. It suggests the starch is not chemically affected by the influence of glycerol during plasticization or the incorporation of different $\mathrm{CNC}$ amounts so, the association could be due to molecular associations exclusively.

The wide band appearing in the range (3400-3200) $\mathrm{cm}^{-1}$ is ascribed to the $\mathrm{O}-\mathrm{H}$ bond stretching vibration mode, corresponding with the inter- and intra-molecular hydrogen bonds in both, starch and cellulose structures. The intensity of this band increases with the plasticization of starch granules due to the formation of hydrogen interactions between starch molecules and glycerol. The same tendency is observed with the incorporation of CNCs, due to the formation of new hydrogen bonds between the cellulose nanocrystals and the TPS matrix (Orue et al. 2016; Salaberria et al. 2015). However, when the amount of $5 \mathrm{wt} \% \mathrm{CNC}$ is added, the intensity of this band remains the same as for nanocomposite with $2 \mathrm{wt} \%$. It seems no more hydrogen interactions between CNCs and TPS could be generated. It can be the reason why aggregates of remaining CNCs can be seen by SEM imaging in the former section.

The band at $1642 \mathrm{~cm}^{-1}$ is related to the bending vibration mode of $\mathrm{O}-\mathrm{H}$ bond in water molecules adsorbed in the amorphous regions of starch so, the changes in the intensity of this band can be attributed to variations in the crystallinity of starch. The CNC incorporation leads to an increasing in the intensity of this band, indicating a higher number of water molecules intercalated in amorphous regions, which produces a decreasing in the crystallinity of the material as was observed by $\mathrm{x}$-ray diffraction analysis in the previous section.

The infrared spectra in the region of stretching vibration modes of $\mathrm{C}-\mathrm{C}$ and $\mathrm{C}-\mathrm{O}$ bonds (1300-800 $\mathrm{cm}^{-1}$ ) is sensible to short-range structural changes as was reported by Van Soest et al. (1995). The granular starch samples were characterized by a wide absorption band centered about $995 \mathrm{~cm}^{-1}$ and a shoulder at $1047 \mathrm{~cm}^{-1}$. They are attributed to the $\mathrm{C}-\mathrm{O}$ bond stretching vibration in $\mathrm{C}-\mathrm{O}-\mathrm{C}$ group of anhydroglucose ring and $\mathrm{C}-\mathrm{O}-\mathrm{H}$ bending bands in crystalline regions of starch, respectively, and they correspond with a double helical conformation on starch structure (Capron et al. 2007). After the plasticization, the peak at $995 \mathrm{~cm}^{-1}$ becomes wider with a higher intensity while the shoulder at $1047 \mathrm{~cm}^{-1}$ becomes less intense and unclear. The spectrum of TWS shows a relatively higher intensity peak at $1022 \mathrm{~cm}^{-1}$ in both: TWS and TWS/CNC spectra than the corresponding to WS, although to a lesser extent in the TWS/CNC biocomposites. This peak at $1022 \mathrm{~cm}^{-1}$ is assigned to the $\mathrm{C}-\mathrm{O}-\mathrm{H}$ bending mode vibration band in the amorphous region of starch, indicating the formation of stable hydrogen bonds between $\mathrm{O}-\mathrm{H}$ groups of glycerol and oxygen atom of both, $\mathrm{C}-\mathrm{O}-\mathrm{H}$ and $\mathrm{C}-\mathrm{O}-\mathrm{C}$ bonds in the anhydroglucose ring, which is considered as a signal of plasticization is well accomplished.

Dynamic mechanical analysis (DMA)

The viscoelastic behavior of bionanocomposites was studied by dynamic mechanical analysis. The curves corresponding to storage modulus, E', (logarithmic scale) and loss factor, $\tan \delta$, versus temperature were obtained for the films previously stored at $40 \%$ of relative humidity for at least 72 h, Fig. 4.

As these materials are expected being used in the food packaging industry, the analysis of mechanical properties was made in a whole range of temperatures. The storage modulus values at $0{ }^{\circ} \mathrm{C},\left(E^{\prime}{ }_{0}\right)$, at $20{ }^{\circ} \mathrm{C}$ ( $E^{\prime}{ }_{20}$, room temperature) and at $50{ }^{\circ} \mathrm{C},\left(E^{\prime}{ }_{50}\right)$, as well as the relaxation temperatures measured from the $\tan \delta$ peaks were obtained for TWS and TWS/CNC films and they are reported in Table 1.

The modulus value increases gradually in the whole range of temperatures. This fact is usually attributed to 

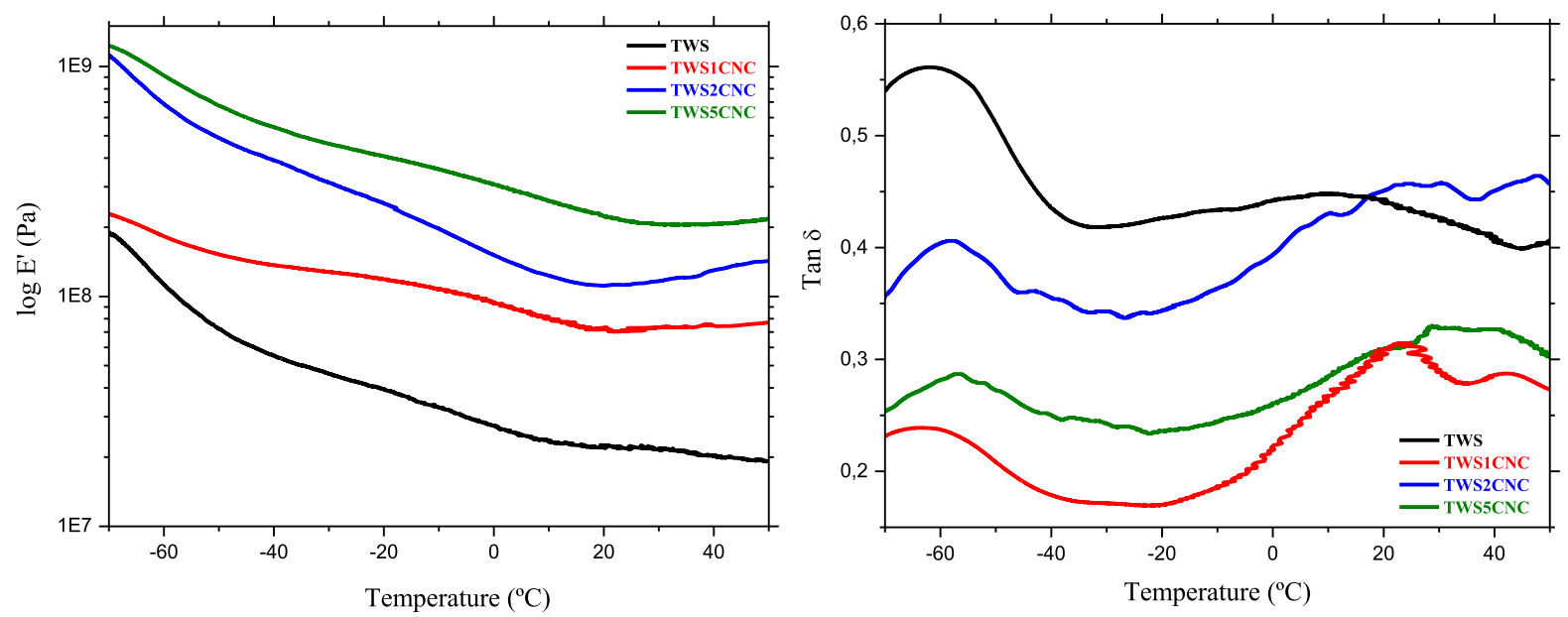

Fig. 4 Evolution (at a frequency of $1 \mathrm{~Hz}$ ) of storage modulus (in logarithmic scale) and loss factor with temperature for TWS and TWS/CNC films

Table 1 Viscoelastic properties of plasticized wheat starch and TWS/CNC nanocomposites

\begin{tabular}{lccccc}
\hline SAMPLE CODE & $\mathrm{E}_{0}^{\prime}(\mathrm{MPa})$ & $\mathrm{E}_{20}^{\prime}(\mathrm{MPa})$ & $\mathrm{E}_{50}^{\prime}(\mathrm{MPa})$ & $\mathrm{T}_{1}\left({ }^{\circ} \mathrm{C}\right)$ & $\mathrm{T}_{2}\left({ }^{\circ} \mathrm{C}\right)$ \\
\hline TWS & 27.4 & 22.4 & 19.7 & -62.1 & 10.1 \\
TWS1CNC & 93.6 & 73.5 & 74.8 & -62.8 & 22.4 \\
TWS2CNC & 152.0 & 112.7 & 140.7 & -58.3 & 24.0 \\
TWS5CNC & 307.5 & 225.3 & 214.9 & -56.5 & 30.4 \\
\hline
\end{tabular}

$\boldsymbol{E}_{\boldsymbol{0}}^{\prime}$ : Storage modulus at $T=0^{\circ} \mathrm{C}$

$\boldsymbol{E}_{20}{ }_{20}$ : Storage modulus at $T=20^{\circ} \mathrm{C}$ (room temperature)

$\boldsymbol{E}^{\prime}{ }_{50}$ : Storage modulus at $T=50^{\circ} \mathrm{C}$

$\boldsymbol{T}_{\boldsymbol{1}}$ and $\boldsymbol{T}_{2}$ are calculated at the maximum of the peak in $\tan \delta$ curves

both factors: a good interaction between the cellulosic filler and the starch matrix due to their chemical similarity, which lead to the appearance of a rigid crystalline network in the interface regions and the semicrystalline structure of cellulose nanocrystals and to their high aspect ratio (Babaee et al. 2015; LomelíRamírez et al. 2014). In fact, the nanocomposites filled with 5 wt. \% CNC show a modulus value more than $1000 \%$ for $E^{\prime}{ }_{0}$ and for $E^{\prime}{ }_{50}$, and more than $900 \%$ for $E_{20}^{\prime}$, all above the neat TWS.

The appearance of two relaxation processes in tan $\delta$ vs $T$ curves manifests the heterogeneous nature of the wheat starch films plasticized with glycerol (García et al. 2009). These peaks are commonly referred to relaxations of the polymer related to glass transition temperature $\left(T_{g}\right)$ or secondary transitions. In case of glycerol plasticized starches, the relaxation at lower temperatures is ascribed to the glass-rubber transition of shorter molecules in glycerol rich domains $\left(\alpha_{1}\right.$ relaxation) while, the process at the higher temperature is associated with the movement of amylopectin chains in amorphous regions into the starch rich domains $\left(\alpha_{2}\right.$ relaxation). Temperature values for these relaxations, $T_{1}$ for $\alpha_{1}$ relaxation and $T_{2}$ for $\alpha_{2}$ relaxation, were calculated at the maximum of the peak found in $\tan \delta$ graphs and they are shown in Table 1. Both temperatures were shifted to higher values as the CNC content increases in the nanocomposite pointing to a decrease of polymer chains mobility into the matrix. In case of $\alpha_{1}$ relaxation, the temperature value increases almost 6 García et al. 2009) which indicates a higher restriction in glycerol chains movement, consequence of the higher rigidity of the matrix. The increment in temperature value is 
higher in $T_{2}$ than in $T_{1}$ so, the mobility of starch chains is affected in a greater extent than the glycerol molecules, which can be attributed to a higher interaction of CNCs with the starch than with the glycerol. Moreover, the jump intensity in $\alpha_{2}$ relaxation clearly decreases and the peaks suffer a widening as CNC content increases, so, the nanoparticles incorporation produces a reduction on the starch chains mobility leading to the increase of the matrix stiffness as observed in the evolution of storage modulus. The composite becomes more viscous and the interfacial adhesion enhances.

\section{Thermal stability}

Thermogravimetric measurements were carried out to assess the thermal decomposition of all the nanocomposites. Thermogravimetric curves (TG) and derivative thermogravimetric curves (DTG) for all the films were reported in Fig. 5. Decomposition profiles for wheat starch granules (WS), pure glycerol (Gly) and CNCs were added to the graphs as a reference.

The wheat starch granules (WS) showed an initial weight loss, about $6.3 \%$, mainly due to the evaporation of water. A single degradation step occurred with an onset at $309^{\circ} \mathrm{C}$ and the temperature of the peak at the maximum degradation rate occurred at $329{ }^{\circ} \mathrm{C}$. CNC profile shows a similar behavior, which is normal according to the structural similarities between starch and cellulose molecules. The water evaporation step occurs with a mass loss about $4.1 \%$. The degradation step starts at a temperature of $334{ }^{\circ} \mathrm{C}$. The char yield obtained from wheat starch at $800{ }^{\circ} \mathrm{C}$ was $13 \%$, while for CNCs was $5 \%$. A second step at higher temperatures for CNCs occurs, leading a minor residue than starch. This second step can be assigned to the degradation of a more thermal resistant component present in cellulose materials. With respect to glycerol, degradation starts at much lower temperatures $\left(208{ }^{\circ} \mathrm{C}\right.$ ) and no remainder is observed at $800{ }^{\circ} \mathrm{C}$.

All the films show three main stages of decomposition: the step at low temperatures $\left(50-120^{\circ} \mathrm{C}\right)$ is ascribed to the evaporation of water. The second stage occurs in the range of temperatures from 120 to $280{ }^{\circ} \mathrm{C}$, which is attributed to the decomposition of glycerol-rich phase of the thermoplastic starch. As the CNC content increases in the film, the mass loss in this stage decreases indicating a more trapping of glycerol molecules in the plasticized starch matrix. The third stage occurs at temperatures higher than $280{ }^{\circ} \mathrm{C}$. This step corresponds with the partially decomposed starch-rich phase oxidation and the degradation of cellulose nanoparticles. The char residue obtained at $800{ }^{\circ} \mathrm{C}$ for the neat TWS films is clearly lower than the obtained for TWS/CNC films at the same temperature, as can be expected due to the higher degradation resistance of the filler.

With respect to the effect of the filler in the temperature values observed in DTG curves for the maximum rate of degradation, a slight shifting towards higher values are observed in TWS/CNC nanocomposites with respect to the neat TWS, maybe due to a

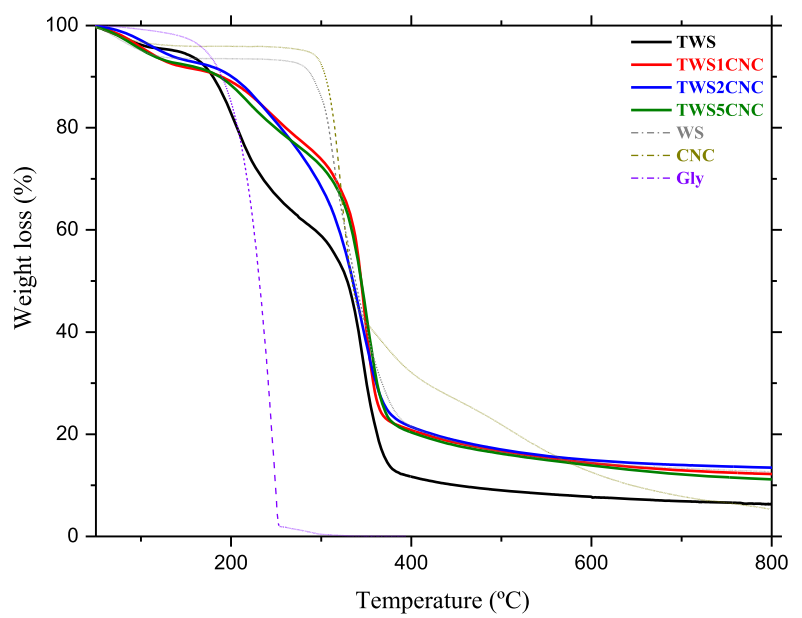

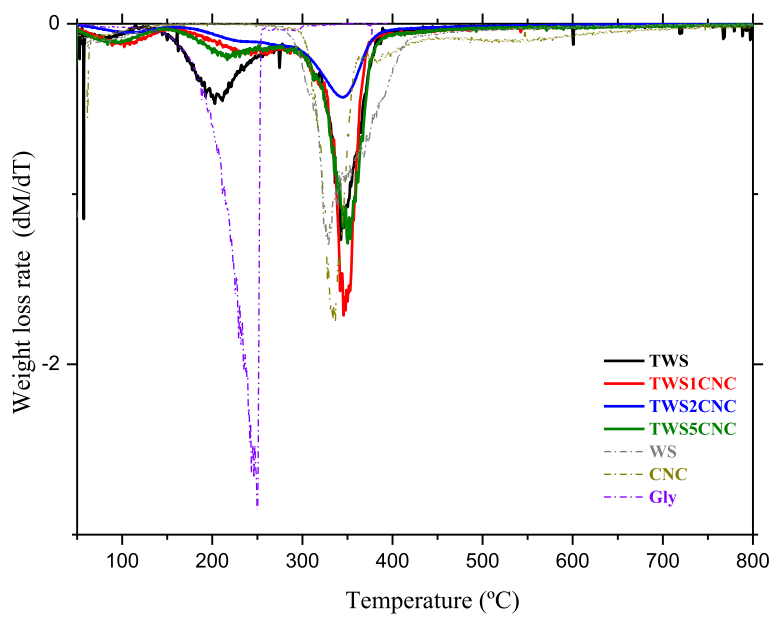

Fig. 5 TGA and DTG profiles obtained for wheat starch granules (WS), pure CNCs and glycerol (Gly) as well as TWS and TWS/CNC nanocomposites 
good interaction between CNCs and TPS matrix and/ or a higher stability of the crystalline structure of CNCs.

\section{Water absorption}

TPS films are highly sensitive to moisture due to the polarity given by the hydroxyl groups in the starch structure. Moisture resistance is required to enhance product integrity in the food packaging industry so, it is important to control water sorption of starch films in searching for a better barrier to water. More hydrophobic cellulose nanoparticles were incorporated to thermoplastic starch matrix to solve this problem. Moreover, the inconvenience of water interaction were reported to worsen the mechanical properties and favoring the degradation of TPS film. CNC incorporation noticeably improves these properties as was reported in the previous sections.

The evolution of water absorption along the time was calculated according to Eq. (1) until equilibrium sorption was reached. The water uptake curves for the neat and filled films, subjected to 54\%, $75 \%$ and $95 \%$ $\mathrm{RH}$, are shown in Fig. 6. The percentage of water molecules absorbed by the TPS films is higher in an ambient with higher relative humidity values. The absorption of water molecules into the matrix favors the starch chains movement increasing the capacity of diffusion through the matrix (Slavutsky and Bertuzzi 2014).

The percentage of water absorbed by TPS in percentage of weight $(\% \mathrm{~W})$ shows an evolution in three different steps along the time. It increases linearly during the early hours of exposure until the maximum value is reached. Then, the percentage of water absorbed remains stabilized, leading to a plateau zone where the equilibrium value $\left(W_{e q}\right)$ is registered. These parameters are summarized in Table 2, showing a decrease in their value as the content of CNCs increases in the matrix. The filler addition produces a resistance to water absorption due to several factors: the higher hydrophobic character and the crystallinity of cellulose nanocrystals and the geometrical impediment created from them as the diffusion of the water molecules inside the matrix as well as swelling of starch is impeded for the formation of a rigid cellulose network. Moreover, the chemical similarity lead to a strong interaction between nanoparticles and starch segmental chains diminishing the amount of free hydroxyl groups, responsible for the TPS hydrophobic character (Teixeira et al. 2009).

In some cases, the films have suffered swelling. They become softer and opaque and even, they turned into yellow at longer times (more than $150 \mathrm{~h}$ ). It can be attributed to the retrogradation process and can be observed as a decrease in the rate of water uptake, especially in the environment with $95 \% \mathrm{RH}$. It is explained by a tendency to remove water and other volatiles out of the matrix, which causes a decrease in the weight of material resulting in a fall line after having reached equilibrium (Montero et al. 2017).

Moisture absorption processes in polymer composites can be described by Fick's second law of diffusion. The expression of this law, can be written according to the Eq. 2.

$\frac{M_{t}-M_{0}}{M_{\infty}}=\frac{4}{L}\left[\frac{D t}{\pi}\right]^{1 / 2}$

where $M_{0}, M_{t}$ and $M_{\infty}$ are the weights of the dried sample, after being exposed to $95 \%$ RH during a time, $t$, and during the equilibrium, respectively. $L$ is the thickness of a film with plane sheet geometry and $D$ is the diffusion coefficient at a constant temperature, in that case at $20 \pm 2{ }^{\circ} \mathrm{C}$.

At short times, when $\left(\frac{M_{t}-M_{0}}{M_{\infty}}<0.5\right)$, the water diffusivity through the films can be analyzed according to the diffusion coefficient from the slope of the $\left(\frac{M_{t}-M_{0}}{M_{\infty}} v s t^{\frac{1}{2}}\right)$ curve. The data obtained are reported in Table 2. CNC incorporation prevents the diffusion of water molecules through the matrix as can be observed by the decrease in the value of diffusion coefficient, D. A good interaction between particle-starch through hydrogen bending prevent the segmental mobility and thus the diffusivity. The highly crystallinity of cellulose nanoparticles creates the tortuous pathways mentioned above, which hinders the molecular diffusion along with the ability of cellulose nanoparticles to form a dense percolating network.

\section{Water/oxygen barrier properties}

The permeability to water vapor can be calculated from the water vapor transmission rate ( $W V T R)$ value. The later constitutes an important parameter to be analyzed in films with potential applications in the food packaging industry. In order to determinate the 
Fig. 6 Water uptake evolution in TWS and TWS/ $\mathrm{CNC}$ materials obtained at relative humidity of 54,75 and $95 \%$
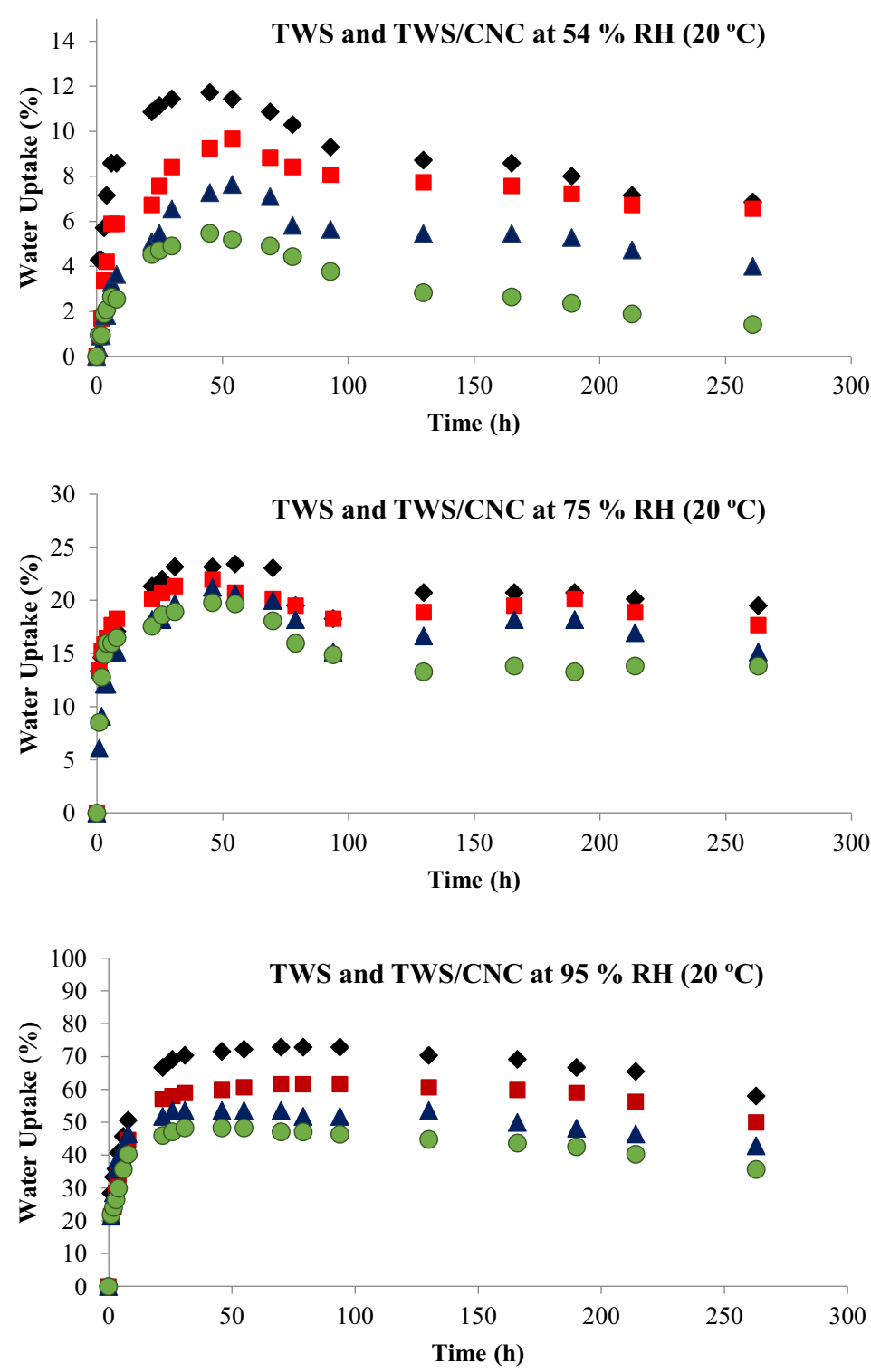

$\bullet$ TWS

-TPWS1CNC

$\triangle$ TPWS2CNC

OTPWS5CNC

$\bullet$ TWS

TPWS1CNC

$\triangle$ TPWS2CNC

OTPWS5CNC

$\bullet$ TWS

TPWS1CNC

$\triangle$ TPWS2CNC

OTPWS5CNC
Table 2 Water uptake at equilibrium $\left(W_{e q}\right)$ values for TWS and TWS/CNC films conditioned at 54\%, 75\% and 95\% $\mathrm{RH}$, Diffusion coefficient (D) and transmission rate obtained for water vapor (WVTR) and oxygen molecules (OTR) through TWS and TWS5CNC films

\begin{tabular}{lllllll}
\hline Film code & \multicolumn{2}{l}{ Water uptake at equilibrium, $\mathrm{W}_{\mathrm{eq}}(\mathrm{wt} \%)$} & $\mathrm{D}\left(\mathrm{m}^{2} \mathrm{~s}^{-1} \times 10^{-14}\right)(95 \% \mathrm{RH})$ & $\mathrm{WVTR} \mathrm{g} \cdot \mathrm{m} /\left(\mathrm{m}^{2} \cdot \mathrm{day}\right)$ & $\mathrm{OTR} \mathrm{cc} /\left(\mathrm{m}^{2} \cdot \mathrm{day}\right)$ \\
\cline { 2 - 4 } & $54 \% \mathrm{RH}$ & $75 \% \mathrm{RH}$ & $95 \% \mathrm{RH}$ & & 427.3 & 339.6 \\
\hline TWS & 11.7 & 23.4 & 72.8 & 3.0 & - & - \\
TWS1CNC & 9.7 & 22.0 & 61.6 & 2.1 & - & - \\
TWS2CNC & 7.6 & 21.2 & 53.6 & 2.0 & 395.8 & 279.3 \\
TWS5CNC & 5.5 & 19.8 & 48.3 & 2.0 &
\end{tabular}


influence of the CNC incorporation in the TWS films in this sense, the water vapor transmission rate values were obtained for the two limit materials analyzed in this study: the neat TWS film (TWS) and the TWS film reinforced with the higher CNC content (TWS5CNC). The results obtained can be seen in Table 2. A reduction in the water vapor transmission rate value can be observed when a $5 \mathrm{wt} \% \mathrm{CNC}$ is incorporated to the TWS matrix. It is known that a direct relation exists between the permeability and the diffusion coefficient $(D)$ of a permeant gas: permeability is obtained as the product of the diffusion coefficient $(D)$ and the solubility $(S)$ of the gas in the matrix. The diffusivity depends of the porosity and tortuosity of the matrix and the solubility depends on the water affinity of the material (Dole et al. 2004). So, the minor WVTR value obtained for the TWS5CNC film, in comparison with the neat TWS film, indicates that the CNC incorporation clearly reduces the diffusion capacity of water vapor molecules, probably due to the formation of a crystalline network of cellulose. Moreover, the efficiency in reducing water vapor transmission rate can be caused as well by the nanometric scale reinforcement of CNCs (García et al. 2009).

The same tests were made to obtain the oxygen transmission rate (OTR) value for the same two materials: neat TWS and TWS5CNC and they are reported in Table 2. As occurs with the WVTR results, the OTR value decreases in $5 \mathrm{wt} \%$ CNC filled TWS film with respect to the obtained for the neat TWS film, which indicates that the percolation network formed by the cellulose nanocrystals in the matrix hinders the oxygen molecules permeation across the thermoplastic starch matrix.

\section{Conclusions}

Bionanocomposite films were obtained from wheat starch and reinforced with cellulose nanocrystals. In the light of the results obtained from the analysis made, these biocomposites films could be adequate for using, as substitutes for petroleum-based polymers, in short-time applications in the food packaging industry. A study of the plasticizing process as well as the final properties of these bionanocomposite films was carried out. The plasticization was complete in the conditions used and favored by the filler addition.
The incorporation of an increasing percentage of cellulose nanocrystals in the wheat starch matrix leads to more rigid films, with a better resistance to ambient moisture and to the gas molecules permeation across the film. These improvements are attributed to several factors such as: the higher starch-cellulose interaction with respect to the glycerol-starch, the high crystallinity of the filler and the formation of a cellulose network, which prevents the movement of the chains, providing rigidity to the matrix, and hindering the passage of gas molecules. In fact, the gas permeation through the matrix was evidenced by the decreasing of water vapor and oxygen transmittance values obtained for bionanocomposites modified with cellulose nanocrystals. Finally, the thermal stability of the materials seems not be affected by the incorporation of the filler.

These bionanocomposite films were revealed as potential candidates to be used in the food packaging industry, where the mechanical resistance and the resistance to the water vapor and gas molecules permeation are fundamental properties.

Acknowledgments The research leading to these results received funding from the Xunta de Galicia Government: program of consolidation and structuring competitive research units [Grant number: ED431C 2019/17]. Funding for open access charge was provided by Universidade da Coruña/CISUG.

Funding Open Access funding provided thanks to the CRUECSIC agreement with Springer Nature.

\section{Declarations}

Conflict of interest The authors declare that this work is in compliance with ethical standards. The authors declare that they have no conflict of interest.

Open Access This article is licensed under a Creative Commons Attribution 4.0 International License, which permits use, sharing, adaptation, distribution and reproduction in any medium or format, as long as you give appropriate credit to the original author(s) and the source, provide a link to the Creative Commons licence, and indicate if changes were made. The images or other third party material in this article are included in the article's Creative Commons licence, unless indicated otherwise in a credit line to the material. If material is not included in the article's Creative Commons licence and your intended use is not permitted by statutory regulation or exceeds the permitted use, you will need to obtain permission directly from the copyright holder. To view a copy of this licence, visit http://creativecommons.org/licenses/by/4.0/. 


\section{References}

Babaee M, Jonoobi M, Hamzeh Y, Ashori A (2015) Biodegradability and mechanical properties of reinforced starch nanocomposites using cellulose nanofibres. Carbohydr Polym 132:1-8. https://doi.org/10.1016/j.carbpol. 2015.06.043

Cao X, Chen Y, Chang PR, Stumborg M, Huneault MA (2008) Green composites reinforced with hemp nanocrystals in plasticized starch. J Appl Polym Sci 109:3804-3810. https://doi.org/10.1002/app.28418

Capron I, Robert P, Colonna P, Brogly M, Planchot V (2007) Starch in rubbery and glassy states by FTIR spectroscopy. Carbohydr Polym 68:249-259. https://doi.org/10.1016/j. carbpol.2006.12.015

Cheng G, Zhou M, Wei Y-J, Cheng F, Zhu P-X (2019) Comparison of mechanical reinforcement effects of cellulose nanocrystal, cellulose nanofiber, and microfibrillated cellulose in starch composites. Polym Compos 40:E365E372. https://doi.org/10.1002/pc.24685

Dole P, Joly C, Espuche E, Alric I, Gontard N (2004) Gas transport properties of starch based films. Carbohydr Polym 58:335-343. https://doi.org/10.1016/j.carbpol. 2004.08.002

Dufresne A, Castaño J (2016) Polysaccharide nanomaterial reinforced starch nanocomposites: a review. Starch-Stärke 68:1-19. https://doi.org/10.1002/star.201500307

Emmambux MN, Taylor JRN (2013) Morphology, physical, chemical, and functional properties of starches from cereals, legumes, and tubers cultivated in Africa: a review. Starch-Stärke 65:715-729. https://doi.org/10.1002/star. 201200263

Farrag Y, Malmir S, Montero B, Rico M, Rodríguez-Llamazares S, Barral L, Bouza R (2018) Starch edible films loaded with donut-shaped starch microparticles. LWT-Food Sci Technol 98:62-68. https://doi.org/10.1016/j.lwt.2018.08.020

García NL, Ribba L, Dufresne A, Aranguren MI, Goyanes S (2009) Physico-mechanical properties of biodegradable starch nanocomposites. Macromol Mater Eng 294:169-177. https://doi.org/10.1002/mame.200800271

George J, Sabapathi SN (2015) Cellulose nanocrystals: synthesis, functional properties, and applications. Nanotechnol Sci Appl 8:45-54. https://doi.org/10.2147/NSA.S64386

Kaushik A, Singh M, Verma G (2010) Green nanocomposites based on thermoplastic starch and steam exploded cellulose nanofibrils from wheat straw. Carbohydr Polym 82:337-345. https://doi.org/10.1016/j.carbpol.2010.04.063

Khan B, Niazi MBK, Samin G, Jahan Z (2017) Thermoplastic starch: a possible biodegradable food packaging material-a review. J Process Eng 40:1-17. https://doi.org/10.1111/ jfpe. 12447

Lomelí-Ramírez MG, Kestur SG, Martínez-González R, Iwakiri S, Bolzon de Muniz G, Flores-Sahagun TS (2014) Biocomposites of cassava starch-green coconut fiber: part IIStructure and properties. Carbohydr Polym 102:576-583. https://doi.org/10.1016/j.carbpol.2013.11.020

Mariano M, El Kissi N, Dufresne A (2014) Cellulose nanocrystals and related nanocomposites: Review of some properties and challenges. J Polymer Sci Pt B- Polym Phys 52:791-806. https://doi.org/10.1002/polb.23490
Montero B, Rico M, Rodríguez-Llamazares S, Barral L, Bouza R (2017) Effect of cellulose nanocrystals as a filler on biodegradable thermoplastic starch films from tuber, cereal and legume. Carbohydr Polym 157:1094-1104. https://doi. org/10.1016/j.carbpol.2016.10.073

Nishiyama Y, Mazeau K, Morin M, Cardoso MB, Chanzy H, Putaux J-L (2010) Molecular and crystal structure of 7-fold $\mathrm{V}$-amylose complexed with 2-propanol. Macromolecules 43:8628-8636. https://doi.org/10.1021/ma101794w

Orue A, Corcuera MA, Peña C, Ezeiza A, Arbelaiz A (2016) Bionanocomposites based on thermoplastic starch and cellulose nanofibers. J Thermoplast Compos Mater 29:817-832. https://doi.org/10.1177/0892705714536424

Reddy MM, Vivekanandhan S, Misra M, Bhatia SK, Mohanty AK (2013) Biobased plastics and bionanocomposites: current status and future opportunities. Prog Polym Sci 38:1653-1689. https://doi.org/10.1016/j.progpolymsci. 2013.05.006

Rico M, Rodríguez-Llamazares S, Barral L, Bouza R, Montero B (2016) Processing and characterization of polyols plasticized-starch reinforced with microcrystalline cellulose. Carbohydr Polym 149:83-93. https://doi.org/10.1016/j. carbpol.2016.04.087

Salaberria AM, Díaz RH, Labidi J, Fernandes CM (2015) Role of chitin nanocrystals on physical, mechanical and functional properties in thermoplastic starch films. Food Hydrocoll 46:93-102. https://doi.org/10.1016/j.foodhyd. 2014.12.016

Slavutsky AM, Bertuzzi MA (2014) Water barrier properties of starch films reinforced with cellulose nanocrystals obtained from sugarcane bagasse. Carbohydr Polym 110:53-61. https://doi.org/10.1016/j.carbpol.2014.03.049

Tan K, Heo S, Foo M, Chew IM, Yoo C (2019) An insight into cnanocellulose as soft condensed matter: challenge and future prospective toward environmental sustainability. . Sci Total Environ 650 Part 1. https://doi.org/10.1016/j. scitotenv.2018.08.402

Teixeira EM, Pasquini D, Curvelo AAS, Corradini E, Belgacem MN, Dufresne A (2009) Cassava bagasse cellulose nanofibrils reinforced thermoplastic cassava starch. Carbohydr Polym 78:422-431. https://doi.org/10.1016/j. carbpol.2009.04.034

Van Soest JJG, Tournois H, de Wit D, Vliegenthart JFG (1995) Short-range in (partially crystalline potato starch determined with attenuated total reflectance Fourier-transform IR spectroscopy. Carbohydr Res 279:201-214. https://doi. org/10.1016/0008-6215(95)00270-7

Zainuddin SYZ, Ahmad I, Kargarzadeh H (2013) Cassava starch biocomposites reinforced with cellulose nanocrystals from kenaf fibers. Compos Interfaces 20:188-199. https://doi. org/10.1080/15685543.2013.766122

Zeppa C, Gouanvé F, Espuche E (2009) Effect of plasticizer on the structure of biodegradable starch/clay nanocomposites: thermal, water-sorption, and oxygen-barrier properties. J Appl Polym Sci 112:2044-2056. https://doi.org/10.1002/ app. 29588

Publisher's Note Springer Nature remains neutral with regard to jurisdictional claims in published maps and institutional affiliations. 